\title{
In situ static and dynamic light scattering and scanning electron microscopy study on the crystallization of the dense zinc imidazolate framework ZIF-zni $\dagger$
}

\author{
Todor Hikov, ${ }^{a}$ Christian A. Schröder, ${ }^{b}$ Janosch Cravillon, ${ }^{b}$ Michael Wiebcke ${ }^{b}$ and \\ Klaus Huber*a
}

Received 7th September 2011, Accepted 29th October 2011

DOI: $10.1039 / \mathrm{c} 1 \mathrm{cp} 22855 \mathrm{~b}$

The kinetics and mechanism of crystallization of the dense zinc imidazolate framework with zni topology, from comparatively dilute methanol solutions containing $\mathrm{Zn}\left(\mathrm{NO}_{3}\right) \cdot 6 \mathrm{H}_{2} \mathrm{O}$ and imidazole with variation of the zinc-to-imidazole ratio, were followed in situ by time-resolved static and dynamic light scattering. The light scattering data revealed that metastable primary particles of about $100 \mathrm{~nm}$ in diameter form rapidly upon mixing the component solutions. After a lag time that is dependent on the imidazole concentration, the primary particles aggregate into secondary particles by a monomer addition mechanism with the primary particles as the monomers.

Complementary scanning electron microscopy revealed that further evolution of the secondary particles is a complex process involving polycrystalline intermediates, the non-spherical morphologies of which depend on the initial zinc-to-imidazole ratio. Time and location of the first appearance of crystalline order could so far not be established. The pure-phase ZIF-zni crystals obtained after $240 \mathrm{~min}$ are twins. The aspect ratio of the tetragonal crystals can be controlled via the zinc-to-imidazole ratio.

\section{Introduction}

Crystalline coordination polymers are under intensive investigation since the early $1990 \mathrm{~s} .{ }^{1}$ Metal imidazolate frameworks, also known as zeolitic imidazolate frameworks (ZIFs), represent a distinct subclass of coordination polymers in which metal cations are bridged by ditopic imidazolate or substituted imidazolate anions (im). ${ }^{2}$ In the case of divalent metal centres such as $\mathrm{M}(\mathrm{II})=\mathrm{Zn}$ or Co with tetrahedral $\mathrm{MN}_{4}$ coordination, the three-dimensional frameworks of composition $\left[\mathrm{M}(\mathrm{im})_{2}\right]$ possess silica/zeolite analogous topologies due to the similarity of the angles at the $\mathrm{M}-\mathrm{im}-\mathrm{M}$ and $\mathrm{Si}-\mathrm{O}-\mathrm{Si}$ bridges $\left(\sim 145^{\circ}\right) .{ }^{2,3}$ As in the case of silica, metal imidazolate frameworks with dense and open framework structures can be distinguished. The latter have become a rapidly developing family of microporous materials with many potential applications in gas storage, ${ }^{4}$

${ }^{a}$ Department of Chemistry, University of Paderborn, Warburger Str. 100,33098 Paderborn, Germany.E-mail: klaus.huber@upb.de; Fax: + 49 5251-60-4208; Tel: + 49 5251-60-2125

${ }^{b}$ Institute of Inorganic Chemistry, Leibniz University Hanover, Callinstr. 9, 30167 Hanover, Germany.

E-mail: Michael.Wiebcke@acb.uni-hannover.de;

Fax: + 49511 762-3006; Tel: + $49511762-3698$

$\dagger$ Electronic supplementary information (ESI) available: Fig. S1:

XRD studies. Fig. S2: $M_{\mathrm{w}}$ and $R_{\mathrm{g}}$ as a function of time $t$ for all three HM series. Fig. S3: XRD, Scherrer analysis. Fig. S4: Structure drawings. See DOI: $10.1039 / \mathrm{clcp} 22855 \mathrm{~b}$ separation, ${ }^{5}$ catalysis, ${ }^{6}$ and sensing. ${ }^{7}$ However, dense metal imidazolate frameworks are of interest in their own right and may possess interesting optical, electric, magnetic, or catalytic properties. ${ }^{8,9}$

Metal imidazolate frameworks are most frequently prepared by precipitation from solution under sub-solvothermal or solvothermal conditions. Although some empirical rules have been established to guide this synthesis, ${ }^{10-12}$ the preparation of new compounds is still mainly a trial-and-error approach. Thus, targeted synthesis of a new theoretically predicted and potentially existing ${ }^{13}$ compound is currently not available. Although high-throughput synthesis is a powerful screening method, ${ }^{4}$ a better understanding of the mechanisms of crystallization is required for tailoring processes and their products. ${ }^{14}$ With this in mind, we recently studied the fast room-temperature formation of the microporous zinc 2-methylimidazolate ZIF-8 with sod framework topology ${ }^{15}$ using in situ time-resolved static light and X-ray scattering methods. ${ }^{16,17}$ The studies revealed complex crystallization processes which, depending on the conditions, involved transient occurrence of small precursor nanoclusters. ZIF-8 crystallization under similar conditions was independently investigated by Venna et al. ${ }^{18}$ using various ex situ techniques, which suggested the occurrence of an intermediate metastable amorphous phase. As a continuation and supplement of our above mentioned work, we have recently started to investigate the crystallization of a dense zinc imidazolate 
framework with zni framework topology (denoted ZIF-zni hereafter). The unique tetrahedral framework structure of ZIF-zni was first determined by Lehnert and Seel and is well documented in the literature. ${ }^{19,20}$ ZIF-zni can be prepared by various methods. ${ }^{19-21} \mathrm{We}$ chose to investigate ZIF-zni formation from supersaturated methanol solutions containing $\mathrm{Zn}\left(\mathrm{NO}_{3}\right)_{2} \cdot 6 \mathrm{H}_{2} \mathrm{O}$ and imidazole (Him) at room temperature, that is, under conditions similar to the above-mentioned ZIF-8 crystallization, arguing that such comparative studies could be particularly helpful to gain detailed understanding of the underlying formation mechanisms of metal imidazolate frameworks. Also, ambient conditions enabled us to employ timeresolved static light scattering (TR-SLS) as a laboratoryavailable method. It enabled following particle formation with regard to mass and size in situ with high time resolution (on the order of about $10 \mathrm{~s}$ ). The latter is particularly favorable in the case of rapid particle formation processes, as we have demonstrated recently for $\mathrm{CaCO}_{3}$ and ZIF-8. ${ }^{16,22}$ We hereby combined in situ TR-SLS with in situ time-resolved dynamic light scattering (TR-DLS) and ex situ scanning electron microscopy (SEM) which represent the first kinetic and mechanistic investigations of ZIF-zni nucleation and growth.

\section{Experimental part}

\section{Materials}

$\mathrm{Zn}\left(\mathrm{NO}_{3}\right)_{2} \cdot 6 \mathrm{H}_{2} \mathrm{O}(99.0 \%)$ and imidazole $(99 \%)$ (Him) was purchased from Aldrich. Methanol ( $\geq 99.8 \%$, HPLC grade) was purchased from VWR. All chemicals were used as received without further purification. Potassium hydroxide $(\geq 85 \%$ ) was supplied by Merck.

\section{Synthesis of ZIF-zni via hand mixing (HM)}

Typically, $3 \mathrm{~mL}$ pre-filtered methanol solution of $\mathrm{Zn}\left(\mathrm{NO}_{3}\right)_{2}$. $6 \mathrm{H}_{2} \mathrm{O}$ was filtered through a $0.2 \mu \mathrm{m}$ CHROMAFIL PET-20/ 25 syringe filter directly into the scattering cell. $3 \mathrm{~mL}$ of Him in methanol, containing $4 \times 10^{-4} \mathrm{M} \mathrm{KOH}$, were then successively filtered into the same cuvette, thus initiating the reaction. The cell was briefly shaken and, subsequently, inserted into the TR-SLS goniometer. The Him content was varied within a $\mathrm{Zn}: \mathrm{Him}: \mathrm{MeOH}$ ratio covering a regime of $1: 1: 2000$ through $1: 8: 2000$ while keeping the $\mathrm{Zn}^{2+}$ and $\mathrm{KOH}$ concentration constant. In all cases, the clear solution slowly became turbid and finally precipitated.

\section{Turbidity measurements}

A Cary 5E spectrometer (Varian Inc.) was used for turbidity measurements. The transmission of solutions mixed as explained above was measured at a wavelength of $632 \mathrm{~nm}$, using rectangular quartz glass cuvettes with a thickness of $1 \mathrm{~cm}$. The transmission data were adjusted to the $2 \mathrm{~cm}$ diameter of the scattering cells. The aim was to have an estimation of the evolution of the sample turbidity, which will enable an appropriate termination of the TR-SLS experiment.

\section{Static light scattering setup and data evaluation}

TR-SLS was carried out on a home built multi-angle goniometer, using a $35 \mathrm{~mW} \mathrm{He}-\mathrm{Ne}$ laser $(\lambda=632.8 \mathrm{~nm})$ as the light source.
It allowed simultaneous recording of the scattering intensity at 2 times 19 fixed angles ${ }^{24}$ covering the range $25.84^{\circ}<\theta<$ $143.13^{\circ}$. Cylindrical quartz glass cuvettes from Hellma with a diameter of $20 \mathrm{~mm}$ were used as scattering cells. In a typical experiment, 1000 scattering recordings, each of which requires $2 \mathrm{~ms}$, were accumulated and then averaged to acquire a scattering curve at time $t$. Recording of an angular dependent curve takes $2 \mathrm{~s}$. The time interval between two adjacent measurements was $10 \mathrm{~s}$. The temperature was $25^{\circ} \mathrm{C}$.

Scattering curves were recorded as the Rayleigh ratio of the particles $\Delta R_{\Theta}$, which was calculated from the difference between the Rayleigh ratio of the particle suspension and that of the solvent at the respective scattering angle $\Theta$. Due to the nature of the experiments, the recorded scattering intensity increased with the particle size and concentration. As the reaction proceeded, this increase eventually caused an overflow in the detector channels. Once such an overflow occurred, the signal of the respective detector had to be discarded from the time of its first appearance onwards. Since the process led to ever larger particles, multiple scattering and the onset of sedimentation ultimately prohibited further analysis of scattering data. The general representation of a scattering curve is shown in eqn (1).

$$
\Delta R_{\Theta}=K c M_{\mathrm{W}} P(q) S(q)
$$

with $K$ being the contrast factor of the species forming in solution. These species are assumed to consist of $\mathrm{Zn}(\mathrm{im})_{2}$ building blocks with concentration $c$ of $\mathrm{Zn}(\mathrm{im})_{2}$ in $\mathrm{g} \mathrm{L}^{-1}$. The $\mathrm{Zn}$ (im) $)_{2}$ concentration was calculated with regard to the initial value of $\left[\mathrm{Zn}^{2+}\right]$ as Him was in excess or at the stoichiometric ratio for all but one of the experiments. An exception was the ratio of $\mathrm{Zn}: \mathrm{Him}: \mathrm{MeOH}: \mathrm{KOH}=$ $1: 1: 2000: 2$, where $c$ was calculated using the initial Him concentration as the sub-stoichiometric species. $M_{\mathrm{w}}$ is the weight averaged molar mass, $P(q)$ is the form factor and $S(q)$ is the structure factor, representing inter-particle interactions. In our case, due to the high dilution, $S(q) \approx 1$. Both factors are given as functions of the momentum transfer $q$.

$$
q=\frac{4 \pi n}{\lambda} \sin (\theta / 2)
$$

where $\lambda=632.8 \mathrm{~nm}$ is the laser wavelength and $n=1.329$ is the refractive index of pure methanol as the solvent. The contrast factor $K$ is calculated as

$$
K=\frac{4 \pi^{2} n^{2}}{N_{\mathrm{A}} \lambda^{4}}\left(\frac{\mathrm{d} n}{\mathrm{~d} c}\right)^{2}
$$

using Avogadro's number $N_{\mathrm{A}}$ and the refractive index increment of zni in methanol $\mathrm{d} n / \mathrm{d} c$. Since a $\mathrm{d} n / \mathrm{d} c$ value for zni was not available, we applied a default value of $\mathrm{d} n / \mathrm{d} c=0.1 \mathrm{~mL} \mathrm{~g}^{-1}$, which was expected to represent the correct order of magnitude of this parameter. Thus, all molar mass values are only apparent values, providing the correct relative measure. Furthermore, the concentrations $\left[\mathrm{Zn}^{2+}\right],\left[\mathrm{im}^{-}\right]$and the number of zni particles are constantly changing over the course of the experiment which makes an accurate extrapolation of eqn (1) to $c=0$ impossible.

We compared three common data evaluation techniques: Zimm, Berry and Guinier representations ${ }^{25-27}$ and found that the latter delivers the most reliable results. Eqn (4) shows the 
relation between signal intensity and $R_{\mathrm{g}}$ according to the Guinier representation. ${ }^{27}$

$$
\log \left[\frac{\Delta R_{\Theta}}{K c}\right] \approx \log \left(M_{\mathrm{w}}\right)-\left[\frac{R_{\mathrm{g}}^{2} q^{2}}{3}\right]
$$

where $R_{\mathrm{g}}$ is the square root of the z-averaged squared radius of gyration.

\section{Dynamic light scattering experiments and data evaluation}

We used a model 5000e compact goniometer system (ALV-Laser Vertriebsgesellschaft, Germany), which allows the simultaneous recording of SLS and DLS. A Nd:YAG laser (Soliton, Germany) with $300 \mathrm{~mW}$, operating at a wavelength of $532 \mathrm{~nm}$, was used as the light source. A C25 Haake thermostat was fixed at a temperature of $25{ }^{\circ} \mathrm{C}$ with a precision of $0.01{ }^{\circ} \mathrm{C}$. The scattering cells used were the same as for the TR-SLS experiments.

In a first series of time resolved DLS experiments analogous to the TR-SLS concentration series, the scattering intensity observed at a scattering angle $\Theta=30^{\circ}$ was analyzed for the respective apparent diffusion coefficient $D$. The high sensitivity of the monitoring detector required adjustments to the laser intensity during the measurement in order to prevent terminal damage of the instrument. The measurement times were $10 \mathrm{~s}$ per point for all concentrations but the sub-stoichiometric ratio $\mathrm{Zn}: \mathrm{Him}: \mathrm{MeOH}=1: 1: 2000$, where the very slow speed of the reaction allowed for $30 \mathrm{~s}$ correlation time per point.

The apparent diffusion coefficients $D$ were transformed into effective hydrodynamic radii using eqn (5)

$$
R_{\mathrm{h}}=\frac{k_{\mathrm{B}} T}{6 \pi \eta D}
$$

where $\eta$ is the viscosity of the solvent, $k_{\mathrm{B}}$ is the Boltzmann constant and $T$ the absolute temperature in $\mathrm{K}$. The effective hydrodynamic radius $R_{\mathrm{h}}$ represents the radius of a hard sphere that diffuses at the same rate as the studied object.

The resulting value for the effective hydrodynamic radius $R_{\mathrm{h}}$ is an approximation since the single angle analysis does not allow extrapolation to zero scattering angle.

The data set and approximation of $R_{\mathrm{h}}$ resulting from the reaction at the sub-stoichiometric ratio had a much higher precision in comparison with the rest of the studied reactions. Moreover, using the CONTIN data analysis developed by Provencher, ${ }^{28}$ we could extract the distribution of decay rates $\Gamma$. This was applied to inspect the size distribution of the sample represented as $\Delta R\left(\Gamma_{\mathrm{i}}\right)$ with the sum of all decay rate fractions $\Gamma_{\mathrm{i}}$ being

$$
\sum_{i=1}^{n} \Delta R\left(\Gamma_{\mathrm{i}}\right)=\Delta R_{\Theta=30^{\circ}},
$$

where $\Delta R\left(\Gamma_{\mathrm{i}}\right)$ is the intensity weighted probability for the decay rate $\Gamma_{\mathrm{i}}$ and $\Gamma=D q$ and $\Delta R_{\Theta}=30^{\circ}$ is the total scattered intensity (net Rayleigh ratio) for the particles at $30^{\circ}$.

Additionally, the $\mathrm{Zn}: \mathrm{Him}: \mathrm{MeOH}=1: 1: 2000$ sample was analysed using a combined DLS/SLS study. Under these conditions, the reaction was sufficiently slow and allowed the recording of the scattering intensity at 13 different scattering angles $\Theta\left(30^{\circ} \leq \Theta \leq 150^{\circ}\right)$ at preselected time points, without being affected by a significant change of the signal. This study provided us with simultaneously measured values for $R_{\mathrm{g}}$ and $R_{\mathrm{h}}$. The $R_{\mathrm{g}} / R_{\mathrm{h}}$ ratio acquired in this manner provided us with further structural and morphological information.

\section{Powder X-ray diffraction}

XRD patterns were recorded at room-temperature on a STOE Stadi-P diffractometer in transmission geometry using $\mathrm{CuK}_{\alpha 1}$ radiation ( $\lambda=1.54059 \AA, \mathrm{Ge}(111)$ monochromator) and a linear position sensitive detector. A silicon standard was used to estimate instrumental peak broadening needed for size determination by Scherrer's equation.

\section{Scanning electron microscopy}

SEM images were taken in secondary electron contrast at an acceleration voltage of $2 \mathrm{kV}$ using a JEOL JSM-6700F field-emission instrument. The powder samples were dispersed on a carbon sample holder.

\section{Results and discussion}

We investigated the formation of ZIF-zni in methanol at room temperature using $\mathrm{Zn}\left(\mathrm{NO}_{3}\right)_{2} \cdot 6 \mathrm{H}_{2} \mathrm{O}$ as metal source at a total of eight different $\mathrm{Zn}$ : Him ratios (1:1-1:8). The procedures yielded pure-phase ZIF-zni as proved by comparison of the experimental XRD patterns with a pattern simulated from crystal structure data (see ESI $\dagger$ ). Under such conditions ZIF-zni crystallization is under kinetic control, since the thermodynamically stable phase at ambient temperature and pressure in the zinc imidazolate system is the dense phase with coi framework topology, $8,20,23$ as some of us have very recently shown by combined theoretical and experimental work. The results of the latter work shall be reported in a separate paper.

\section{Transmission measurements}

UV-VIS spectroscopy was used to identify the onset and evolution of turbidity prior to our TR-SLS experiments. High turbidity has to be avoided as it causes multiple scattering. Along this line, transmission values larger than $90 \%$ were considered still amenable to our TR-SLS analysis. Fig. 1 represents two series of transmission experiments conducted on the dilution series of $\mathrm{Zn}: \mathrm{MeOH}=1: 1000$ and $1: 2000$ using the HM procedure. Clearly, the higher dilution provided a much larger time frame for studying the growth in situ. Thus, all experiments presented here were conducted using a $\mathrm{Zn}: \mathrm{MeOH}$ ratio of $1: 2000$.

\section{Time resolved static light scattering studies}

The HM concentration series was conducted three times in order to illustrate the reproducibility of such experiments. The results of the calculation of the apparent molecular weight $M_{\mathrm{w}}$ and the radius of gyration $R_{\mathrm{g}}$ of the third series are shown in Fig. 2 as a representative example (the remaining data are provided in the ESI $\dagger$ ). It is evident that increasing the concentration of the bridging ligand speeds up the process.

Fig. 3 represents a dual plot of the apparent mass $M_{\mathrm{w}}$ and the $R_{\mathrm{g}}$ of the particles for the ratio $\mathrm{Zn}: \mathrm{Him}: \mathrm{MeOH}=$ $1: 6: 2000$ as a representative example. It clearly illustrates a two stage process. 


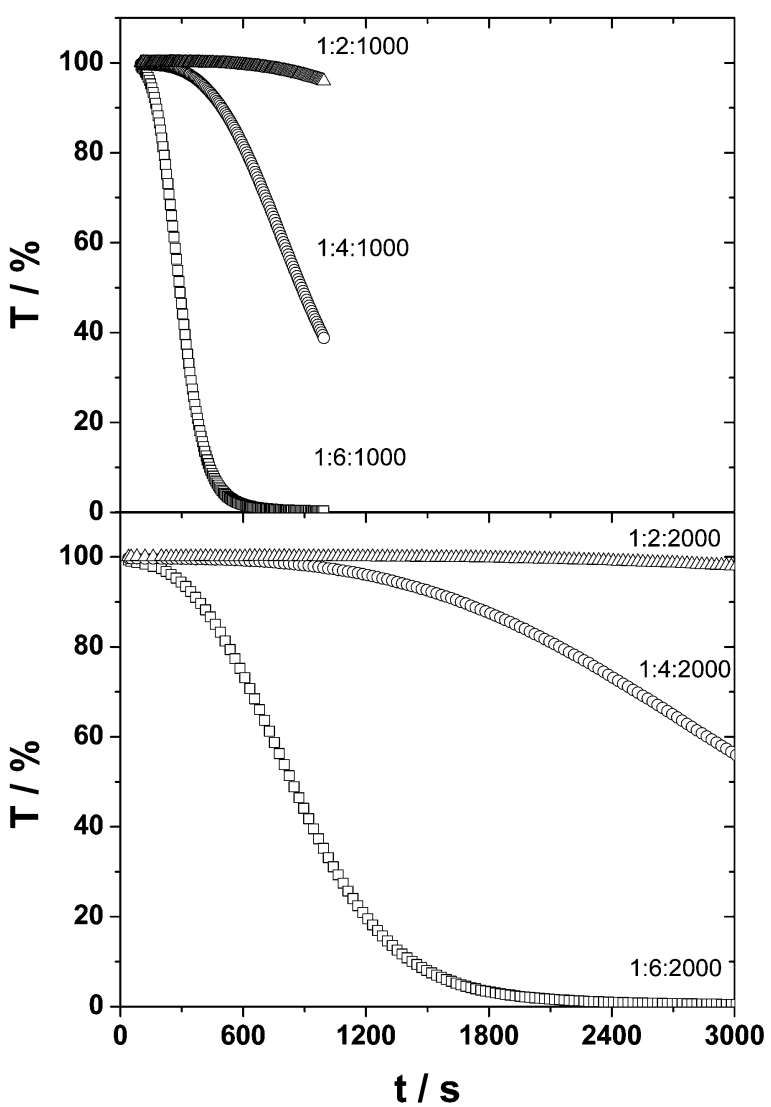

Fig. 1 Transmission T versus time $t$ for experiments at $\mathrm{Zn}: \mathrm{Him}: \mathrm{MeOH}$ ratios of $1: x: 1000$ and $1: x: 2000$.

During the first 200-600 s primary particles were formed with constant values for $R_{\mathrm{g}}$. The variation of the bridging ligand concentration did not affect the size of these initial particles or the structure of the final product. The increased size of the initial particles (a factor of 2) for the $\mathrm{Zn}$ : Him ratios $1: 6,1: 7$ and $1: 8$ is accidental and could not be reproduced by the other two series. Hence an averaged size value of the primary particles was established as $R_{\mathrm{g}}=60 \mathrm{~nm}$ $( \pm 18 \mathrm{~nm})$. While $R_{\mathrm{g}}$ remained constant, the particle mass $M_{\mathrm{W}}$ increased during the first stage of the process. In our case, such behavior is attributed to a slow nucleation process concomitant with a fast particle growth. The individual particle growth comes to a standstill at a particle size of roughly $60 \mathrm{~nm}$.

It should be noted that the weight averaged mass values $M_{\mathrm{W}}$ and the z-averaged squared size values $R_{\mathrm{g}}^{2}$ correspond to the second and the third moment of the particle mass distribution respectively. This means that the z-averaged $R_{\mathrm{g}}^{2}$ values weight larger particles stronger than the weight averaged $M_{\mathrm{w}}$ values do in a broad size distribution. Consequently, the weight averaged mass value, in an ensemble with a continuously increasing number of particles of constant final size, still increases while the respective z-averaged squared radius has already approached its final value. ${ }^{16}$ The particles, resulting from stage one $\left(R_{\mathrm{g}}\right.$ of $\left.60 \mathrm{~nm}\right)$, can be regarded as metastable intermediates of the reaction. Their concentration eventually rises beyond a certain threshold and the second stage of the growth process commences. The latter is characterized by an

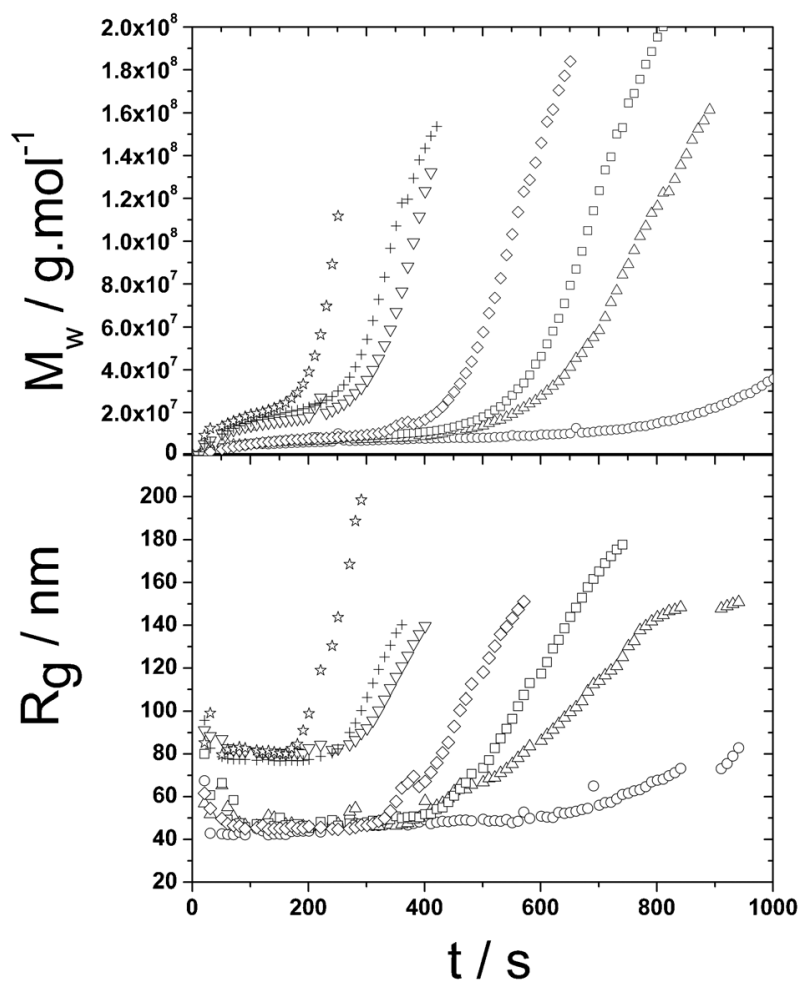

Fig. 2 Overview of the experiments from the $3^{\text {rd }} \mathrm{HM}$ series. Top graph represents the evolution of particle mass $M_{\mathrm{w}}$ with time $t$ and the lower graph shows the evolution of the particle size $R_{\mathrm{g}}$ with time $t$. The $\mathrm{Zn}$ : Him ratios shown are: $\bigcirc 1: 2 ; \triangle 1: 3 ; \square 1: 4 ; \diamond 1: 5 ; \nabla$ $1: 6 ;+1: 7 ;$ it $1: 8$.

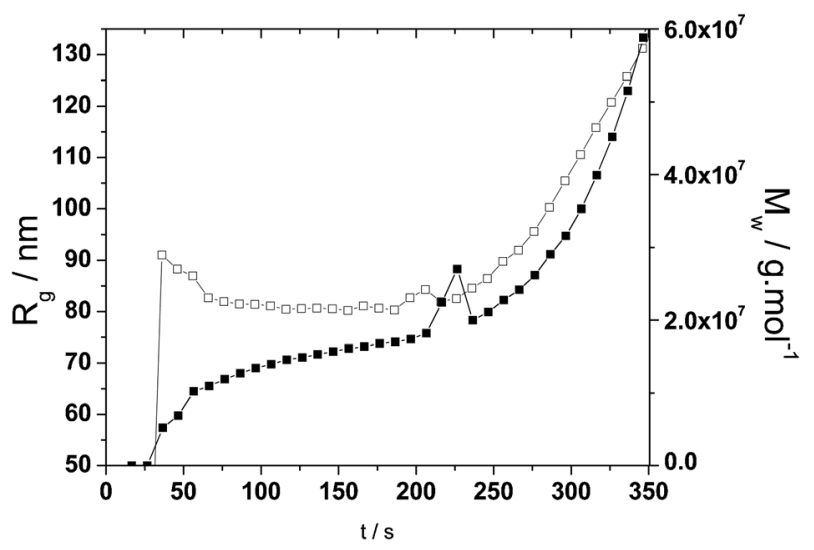

Fig. 3 A comparison between the evolution of the particle mass $M_{\mathrm{W}}$ and the particle size $R_{\mathrm{g}}$ with time $t$. The $\mathrm{Zn}$ : Him ratio is $1: 6$. The symbols represent $R_{\mathrm{g}}$ values ( $\square$ ) and $M_{\mathrm{W}}$ values ( $\boldsymbol{\square}$ ).

increase of $M_{\mathrm{w}}$ at a considerably higher rate in comparison with stage one. In contrast with the first stage, here the size of the scattering species also increases rapidly, pointing to a different type of process. The growth process could be monitored until particles reached a size of about $200 \mathrm{~nm}$. Further observation was impeded by turbidity, resulting in multiple scattering phenomena, and by the eventual precipitation of the growing particles.

An extremely slow reaction speed was observed for the substoichiometric ratio $\mathrm{Zn}: \mathrm{Him}=1: 1($ not shown in Fig. 2$)$ in 


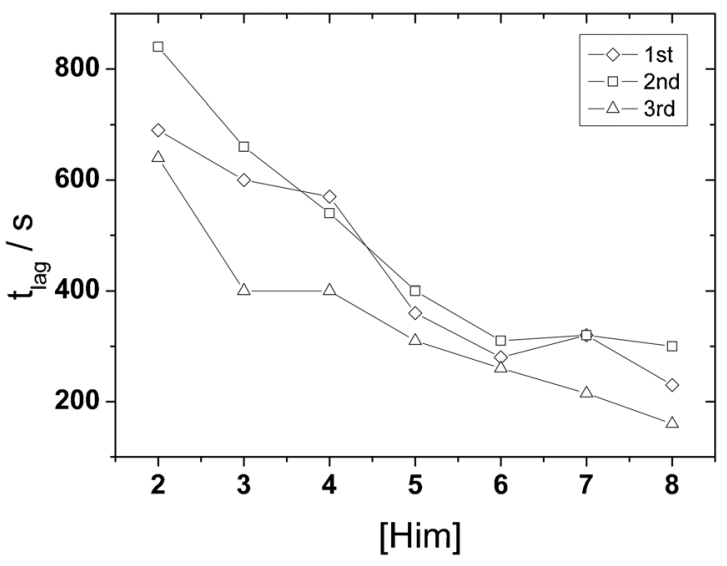

Fig. 4 Lag times $t_{\text {lag }}$ as a function of the Him : Zn ratio. The symbols have the following meaning: $\diamond 1^{\text {st }} \mathrm{HM}$ series; $\square 2^{\text {nd }} \mathrm{HM}$ series; $\triangle 3^{\text {rd }}$ HM series.

comparison with all other ratios. This enabled additional TR-DLS analysis which will be discussed separately later on.

The time required for the onset of the second stage strongly depends on the concentration of the bridging ligand. This time, denoted as lag time $t_{\text {lag }}$, is plotted for all studied samples versus the concentration of the bridging ligand in Fig. 4. It shows that the HM procedure is broadly reproducible and provides consistent results. The lag time has been defined as the time where the size $R_{\mathrm{g}}$ also starts to increase significantly.

It is at this time where $R_{\mathrm{g}} / M_{\mathrm{W}}$ data pairs were used to establish the correlation plots which will give further insight into the second stage of the particle formation process. The relationship between the two parameters extracted from the scattering curves provides structural as well as mechanistic information about the process. It may be used to determine the shape of the investigated particles. In the case of self-similar objects, the correlation yields a simple power law of the following type:

$$
R_{\mathrm{g}} \approx M_{\mathrm{w}}^{\alpha}
$$

Based on a purely geometrical argument, the exponent $\alpha$ is $1 / 3$ for spherical or cubic dense particles, 1/2 for Gaussian coils, and 1 for infinitely thin rods. This exponent bears a different meaning in a kinetic experiment where it is influenced by polydispersity and a bias in the concentration. ${ }^{22}$

A process based on growth by coagulation of liquid like droplets was solved theoretically by Smoluchowski. ${ }^{29}$ In this scenario, any two particles would coalesce if they get closer to each other than the sum of their radii. The corresponding exponent in this process is $1 / 3$, as polydispersity adopts its final value soon after the onset of the reaction. ${ }^{22}$ In contrast, a value of $1 / 6$ is expected for spheres growing through monomer addition. In the latter case the particles grow through the gradual incorporation of monomers with the same scattering contrast as that of the final product. ${ }^{22,30}$

In our case, the relationship between $R_{\mathrm{g}}$ and $M_{\mathrm{w}}$ (Fig. 5) is more complicated since the curves are bent. However, the fact that the data overlay perfectly is an indication that the same process is taking place at each of the studied concentrations.

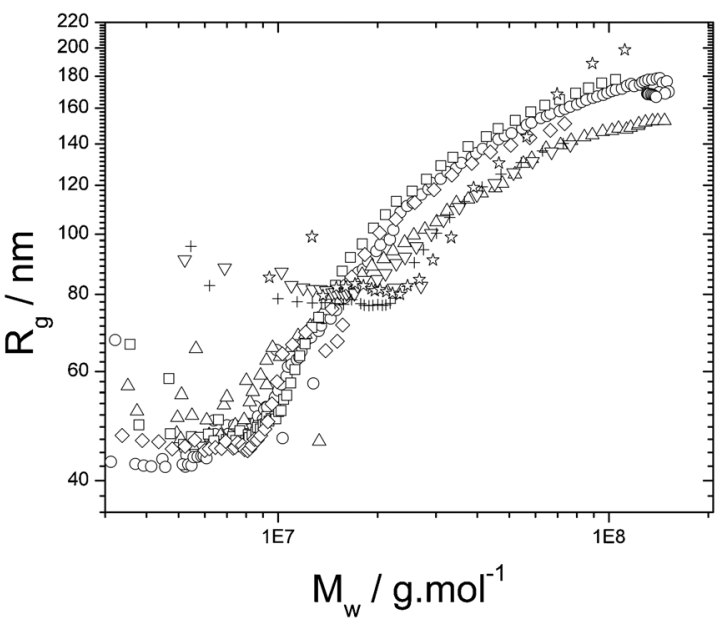

Fig. 5 Correlation between particle size $R_{\mathrm{g}}$ and particle weight $M_{\mathrm{w}}$ for the $3^{\text {rd }} \mathrm{HM}$ series. The $\mathrm{Zn}:$ Him ratios shown here are: $\bigcirc 1: 2 ; \triangle$ $1: 3 ; \square 1: 4 ; \diamond 1: 5 ; \nabla 1: 6 ;+1: 7 ;$ 放 $1: 8$

The lack of a clear cut power law does not exclude a monomer addition mechanism, as the bending (Fig. 5) may correspond to the approach of the limiting scaling behavior. Hence, an interpretation with a monomer addition based growth shall be undertaken under the assumption that the metastable primary particles resulting at the end of the first stage are the monomers. Theoretical values for the z-averaged $R_{\mathrm{g}}^{2}$ and weight averaged $M_{\mathrm{w}}$ were calculated as follows

$$
\begin{gathered}
M_{\mathrm{w}}=\frac{\left(N_{\mathrm{T}}-n_{\mathrm{P}}\right) M_{0}^{2}+M_{\mathrm{P}}^{2}}{N_{\mathrm{T}} M_{0}} \\
R_{\mathrm{g}}^{2}=\frac{\left(N_{\mathrm{T}}-n_{\mathrm{P}}\right) M_{0}^{2} R_{\mathrm{g} 0}^{2}+M_{\mathrm{p}}^{2} R_{\mathrm{gP}}^{2}}{\left(N_{\mathrm{T}}-n_{\mathrm{P}}\right) M_{0}^{2}+M_{\mathrm{p}}^{2}}
\end{gathered}
$$

Eqn (8) and (9) describe a monomer addition scenario with $N_{\mathrm{T}}$ the total number of monomeric units available to one growing secondary particle, each with a radius of gyration $R_{\mathrm{g} 0}$ and mass $M_{0}$. During the course of the reaction, an increasing number $n_{\mathrm{P}}$ of these units are incorporated into aggregates with shape and density equal to that of the monomers. A simple spherical shape has been adopted in the present study. Furthermore, the resulting aggregates are monodisperse and have a mass

$$
M_{\mathrm{P}}=n_{\mathrm{P}} M_{0}
$$

and a size of

$$
R_{\mathrm{gP}}^{2}=\left(n_{\mathrm{P}}^{1 / 3} R_{\mathrm{go}}\right)^{2} .
$$

The values for $R_{\mathrm{g} 0}$ and $M_{0}$ were taken directly from the experimental data at the end of the respective first stage. Thus they were predetermined from the experiment for each kinetic run. The total number of monomers available per growing particle $N_{\mathrm{T}}$ was varied to fit the model curve to the experimental data. Aside from $N_{\mathrm{T}}$, the fit reveals an extent of conversion $\alpha_{\mathrm{P}}=\frac{n_{\mathrm{P}}}{N_{\mathrm{T}}} \times 100$ as a function of time.

The solid lines in Fig. 6 are theoretically modeled curves where the aggregate concentration increases at the expense of monomers. The model curves are in excellent agreement with 


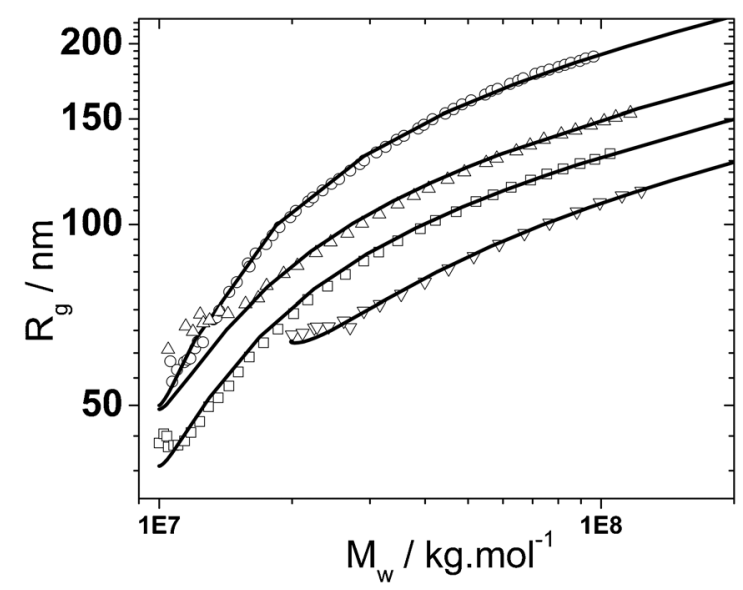

Fig. 6 A theoretical approximation of the experimental data using the monomer addition growth model. The figures show the following ratios of $\mathrm{Zn}:$ Him: $\bigcirc 1: 2 ; \triangle 1: 3 ; \square 1: 4 ; \nabla 1: 6$. The solid lines show theoretical approximations according to a monomer addition model with a fixed $N_{\mathrm{T}}$ value.

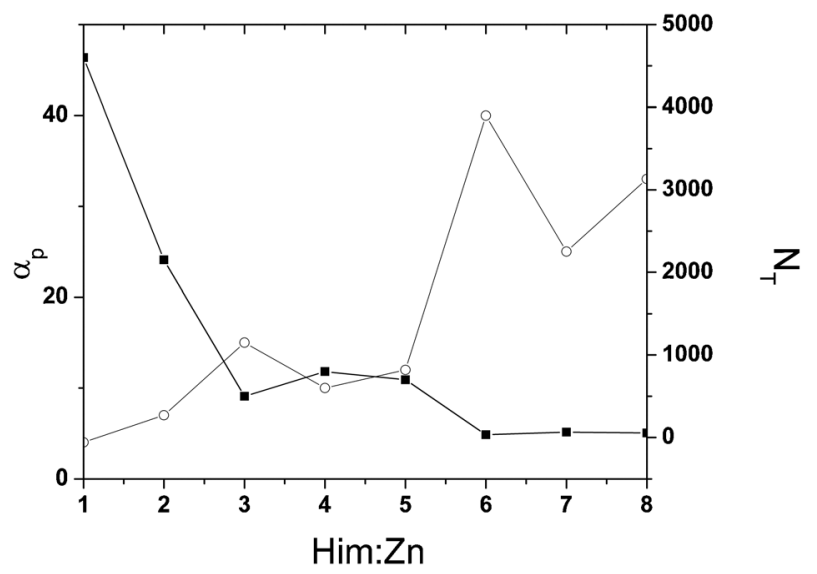

Fig. 7 A representation of the fit parameter $N_{\mathrm{T}}(\boldsymbol{\square})$ and of $\alpha_{\mathrm{p}}$ at the end of the experiment $(\bigcirc)$ versus the Him : $\mathrm{Zn}$ ratio.

the experimental data. In addition, $N_{\mathrm{T}}$ from each fit and $\alpha_{\mathrm{P}}$ established at the end of the respective TR-SLS analysis are summarized in Fig. 7. It shows that the conversion achieved at the end of each recording increases with increasing Him concentration. More importantly, the number of monomers $N_{\mathrm{T}}$ required for achieving a good fit decreases with increasing Him concentration. Since $N_{\mathrm{T}}$ corresponds to the number of monomers available per growing particle, and assuming a similar total quantity of monomer particles at the beginning of stage two for each kinetic run, the number of growing particles is increasing with increasing Him concentration. In a crude approximation, the first stage may be considered to be a 'monomer' formation process, where the formed metastable primary particles are the 'monomers'. At the end of the lag time $t_{\text {lag }}$ a critical amount of 'monomers' has been formed to initiate the second stage. Stage two can be considered as secondary particle formation via 'monomer' incorporation. In such a scenario, the afore mentioned relation between $N_{\mathrm{T}}$ and the concentration of Him would suggest an increased rate of nucleation of secondary particles with increasing Him concentration, which is in line with our experimental observations.

At this point, we have to emphasize that the data could be fitted just as well with a scenario where the number of total monomers $N_{\mathrm{T}}$ and the number of incorporated monomers $n_{\mathrm{p}}$ increase (not shown here) while the transient amount of free monomers $N_{\mathrm{T}}-n_{\mathrm{p}}$ is kept constant as the monomers incorporated into the aggregates are replenished by an on-going formation of new 'monomer' particles with $M_{0}$ and $R_{\mathrm{g} 0}$. Thus, it is beyond the capabilities of this model to distinguish between a process where the number of monomers diminishes during the aggregate formation and a process where monomer formation continues during the second stage of the process.

Furthermore, we implemented cluster-cluster aggregation models where the growth of the aggregates is diffusion or reaction limited, which are the most common and well-studied forms of colloid aggregation. The process begins in a suspension of monodisperse particles, i.e. at the end of stage one in our study. They collide and aggregate irreversibly to form ever larger particles or clusters, resulting in a particle ensemble with a broad size and weight distribution. Importantly, each particle is ready to react irreversibly with any other particle. We will be discussing two modes of cluster-cluster aggregation which correspond to rapid and slow aggregation and have been well established in the literature. ${ }^{31,32}$

In the diffusion limited cluster aggregation mechanism the repulsive energy barrier between the particles is much smaller than $k_{\mathrm{B}} T$ and thus each collision between any two particles results in irreversible aggregation. Therefore, the reaction speed is limited only by the rate of particle diffusion in solution. The correlation describing the expected kinetics for diffusion limited clustercluster aggregation has been derived ${ }^{31}$ as follows

$$
R_{g} \cong a\left(\frac{t}{t_{0}}\right)^{\frac{1}{d_{f}}}
$$

where $t$ is the elapsed time and $t_{0}$ is a characteristic time constant dependent on the initial particle concentration.

In other words $R_{g} \approx t^{1 / d_{f}}$ as a power law is expected and in a double logarithmic representation the function $R_{\mathrm{g}}(t)$ should be a straight line with a slope of $1 / d_{\mathrm{f}}$. The data representation for diffusion limited cluster-cluster aggregation is shown in Fig. 8.

In the reaction limited cluster-cluster aggregation mechanism, the repulsive energy barrier between two approaching particles is comparable to or larger than $k_{\mathrm{B}} T$. Thus, many collisions must occur before two particles react with each other and the aggregation speed is expected to be much slower. In analogy with the diffusion limited case, the particle aggregation here also leads to clusters, which in turn diffuse and react with other particles (clusters), leading again to a broad weight and size distribution of the resulting particle ensemble. ${ }^{31} \mathrm{~A}$ simple exponential has been derived for the reaction limited cluster-cluster aggregation process:

$$
R_{g} \approx \exp \left(\frac{t}{t_{0}}\right)
$$

The reaction limited data representation is shown in Fig. 9. The lack of linear dependencies observed for all concentrations suggests that such processes are not compatible with the aggregation mechanism observed for stage two of our present study. 


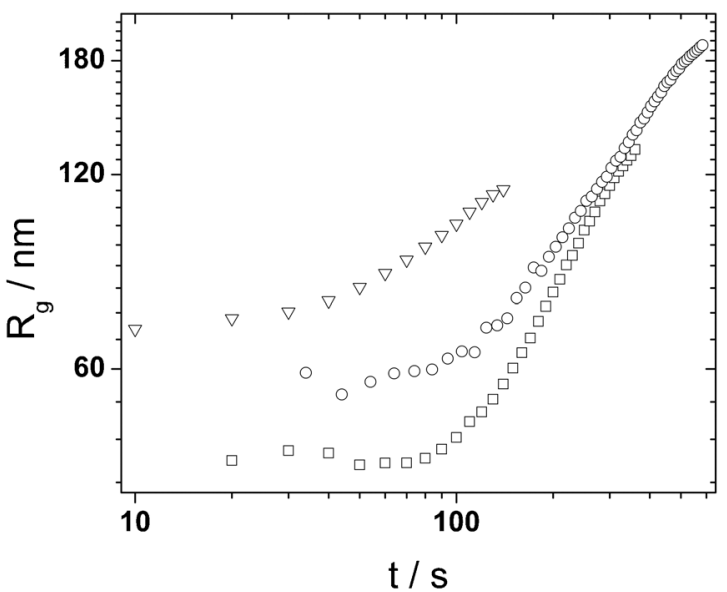

Fig. 8 Double logarithmic representation of the relationship of size $R_{\mathrm{g}}$ with time $t$. The $\mathrm{Zn}$ : Him ratios shown here are as follows: $1: 2$ $(\bigcirc) ; 1: 4(\square) ; 1: 6(\nabla)$. A linear dependency is expected for a diffusion limited aggregation process.

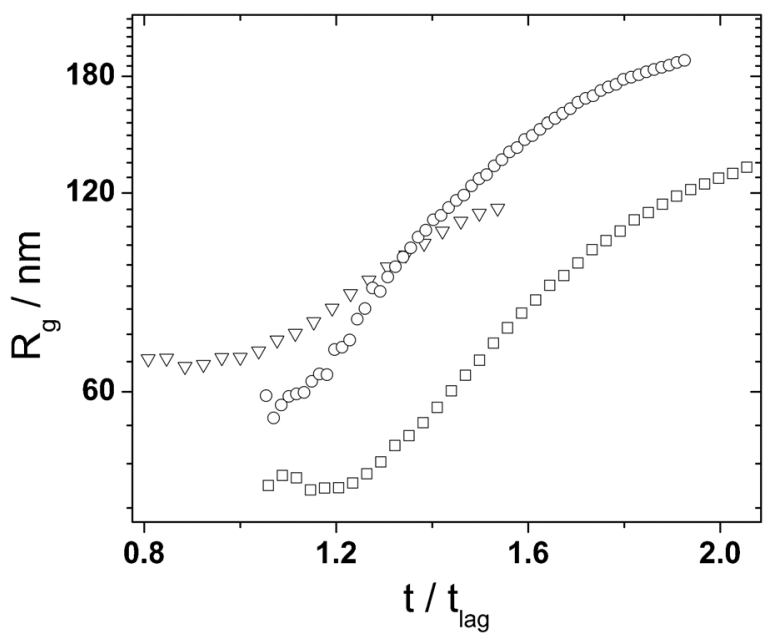

Fig. 9 Representation of the relationship of logarithmic $R_{\mathrm{g}}$ versus $t / t_{\text {lag }}$. The $\mathrm{Zn}$ : Him ratios shown here are as follows: $1: 2(\bigcirc) ; 1: 4$ $(\square) ; 1: 6(\nabla)$. A linear dependency is expected for a reaction limited aggregation process.

The combined data confirm our hypothesis that formation of metastable primary particles with $R_{\mathrm{g}}$ of $60 \mathrm{~nm}$ establishes stage one corresponding to an accumulation of particles rapidly growing to their final size of $R_{\mathrm{g}}=60 \mathrm{~nm}$. The latter eventually reach a critical concentration, necessary to induce stage two growth, which follows a monomer addition mechanism. The primary particles serve as 'monomers' in the second stage and the time required to reach the critical concentration $t_{\text {lag }}$ is strongly dependent on the initial Him quantity. However, it remains unsettled from the above presented data whether formation of monomer particles extends into the second stage of the process.

\section{Dynamic light scattering studies}

In order to clarify whether monomer formation continues during the second stage of the observed process, we followed the particle formation using time resolved dynamic light

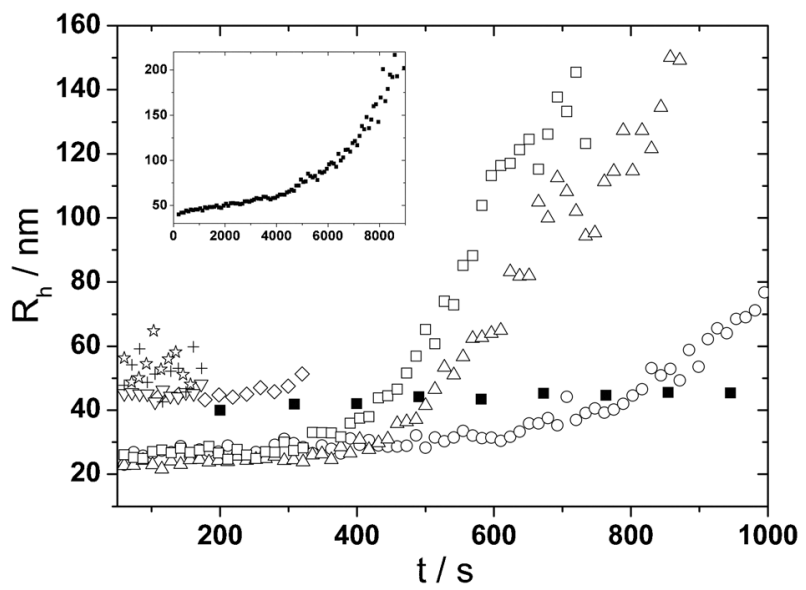

Fig. 10 DLS studies on a series HM experiments showing the hydrodynamic radius $R_{\mathrm{h}}$ as a function of time. The $\mathrm{Zn}:$ Him ratios shown here are: $\square 1: 1 ; \bigcirc 1: 2 ; \triangle 1: 3 ; \square 1: 4 ; \diamond 1: 5 ; \nabla$ $1: 6 ;+1: 7 ;$ is $1: 8$. The inset shows the full $1: 1$ data set.

scattering (TR-DLS). The measurements resulted in calculation of the effective hydrodynamic radii and their distribution.

Due to the steep increase of the scattering intensity, most of the experiments corresponding to higher Him concentrations had to be stopped before completion of the second stage. The results of the TR-DLS series are summarized in Fig. 10. The inset represents the slowest reaction as it has a very much longer time scale with $t_{\mathrm{lag}} \approx 4500 \mathrm{~s}$. The observed trends agree well with those established in Fig. 2.

The slowest reaction allowed for longer data collection at each data point and thus provided higher quality data of the decay time distribution, enabling application of the CONTIN fit routine. ${ }^{28}$ As demonstrated by the $3 \mathrm{D}$ plot in Fig. 11, a slow mode can be distinguished from a fast mode from $t=6000 \mathrm{~s}$ onwards.

One can clearly see the formation of the smaller primary particles during stage one and their subsequent inclusion into the larger structures formed during stage two. The monomer

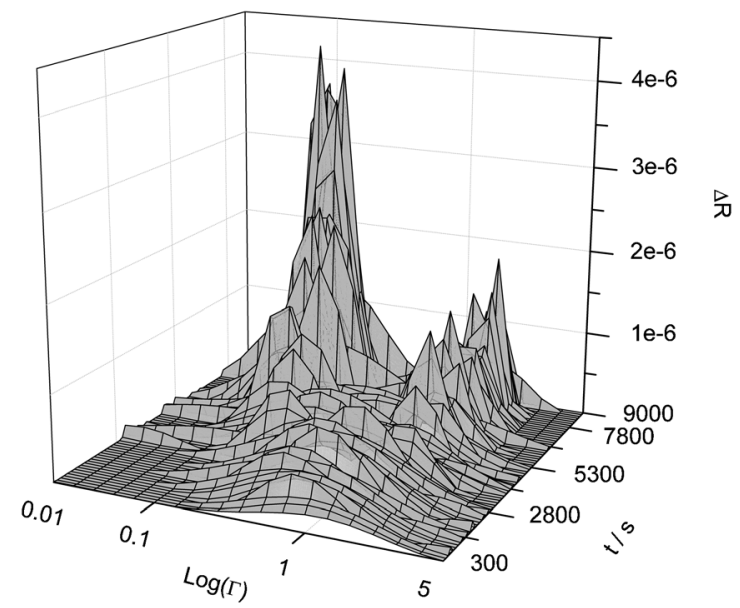

Fig. $113 D$ representation of the distribution of the inverse delay times $\Gamma$ (in logarithmic scale) as a plot of $\Delta R$ versus $\log (\Gamma)$ and time $t$ for $\mathrm{Zn}: \mathrm{Him}: \mathrm{MeOH}=1: 1: 2000$. The total area under the distribution corresponds to the respective total $\Delta R_{\Theta}=30^{\circ}$ established by DLS. 


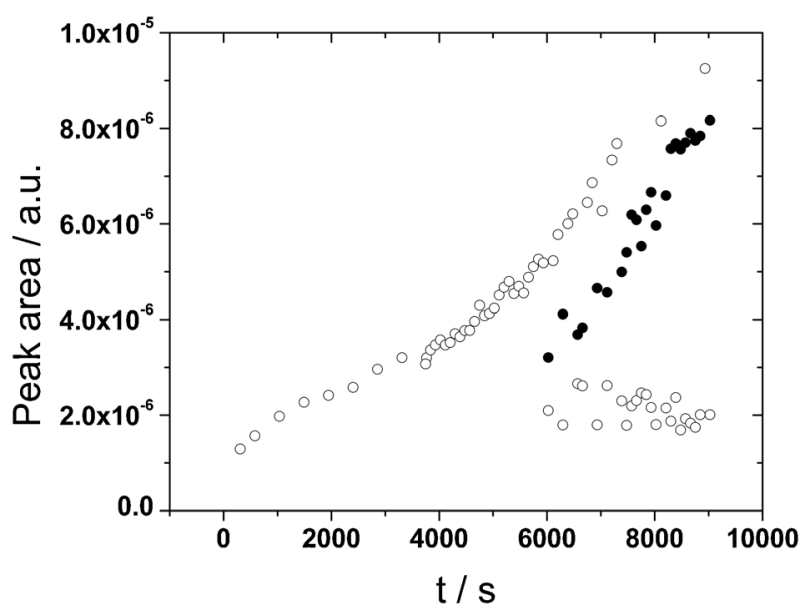

Fig. 12 The evolution of the integrated peak area of the faster mode $\Gamma_{1}(\bigcirc)$ (particles with $R_{\mathrm{h}}$ of $c a .45 \mathrm{~nm}$ ) and the slow mode $\Gamma_{2}(\bullet)$ from Fig. 11 with time. The integrated peak area of $\Gamma_{1}$ corresponds to the scattering intensity attributed to the species with the fast mode and is considered to be a measure of the amount of 'monomer' particles.

quantity remains relatively stable during the observation period. The data are summarized in Fig. 12. The integrated area of the first peak $\left(\Gamma_{1}\right)$ corresponds to the scattering contribution of the 'monomers'. $R_{\mathrm{h}}$ for this mode is about $45 \mathrm{~nm}$. In contrast, the integrated peak area of the slower mode $\left(\Gamma_{2}\right)$ increases steadily during the whole observation period. Such a trend is in favor of a process where the incorporated 'monomer' particles are replenished.

In an additional experiment, we did simultaneous measurement of TR-DLS and TR-SLS on a sample with the sub-stoichiometric ratio $\mathrm{Zn}: \mathrm{Him}: \mathrm{MeOH}=1: 1: 2000$. The simultaneous recording of $R_{\mathrm{g}}$ and $R_{\mathrm{h}}$ using a combined SLS/DLS study required a very long reaction time, as the angular dependent measurement time was about $3 \mathrm{~min}$. Precise measurements require a constant scattering signal to occur during the measurement of a correlation function. This prerequisite was realized only when employing the substoichiometric ratio mentioned above.

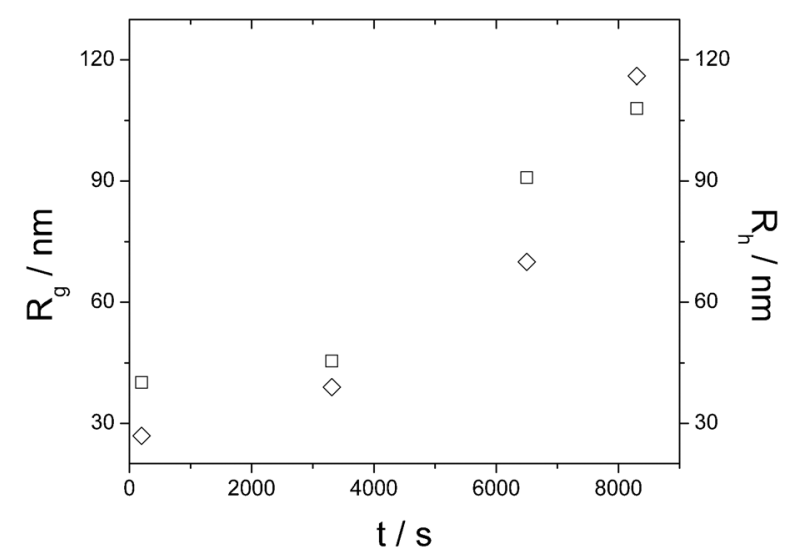

Fig. 13 A comparison of the hydrodynamic radius $R_{\mathrm{h}}$ and radius of gyration $R_{\mathrm{g}}$ as a function of time $t$ from the combined SLS/DLS study on $\mathrm{Zn}: \mathrm{Him}: \mathrm{MeOH}=1: 1: 2000$. The symbols represent $R_{\mathrm{g}}(\diamond)$ and $R_{\mathrm{h}}(\square)$.
Table 1 Results of the combined SLS/DLS study on the substoichiometric $\mathrm{Zn}: \mathrm{Him}: \mathrm{MeOH}=1: 1: 2000$

\begin{tabular}{lccl}
\hline Time $/ \mathrm{s}$ & $R_{\mathrm{g}} / \mathrm{nm}$ & $R_{\mathrm{h}} / \mathrm{nm}$ & $R_{\mathrm{g}} / R_{\mathrm{h}}$ \\
\hline 200 & 26.9 & 40.16 & 0.66982 \\
3310 & 39 & 45.45 & 0.85809 \\
6500 & 70 & 90.83 & 0.77067 \\
8300 & 116 & 108 & 1.07407 \\
\hline
\end{tabular}

The graph shown in Fig. 13 represents a comparison between the hydrodynamic radius $R_{\mathrm{h}}$ and the $R_{\mathrm{g}}$. The $R_{\mathrm{g}} / R_{\mathrm{h}}$ ratio bears additional structural information. It was found to be 0.77 for a compact sphere, 1.3 for a polymer coil under theta-conditions and 1.5 for an expanded coil and $\geq 2$ for rods. ${ }^{33}$ Values falling in between may be considered transient between the two limiting cases. The values calculated for the slow, sub-stoichiometric reaction mixture $\mathrm{Zn}: \mathrm{Him}: \mathrm{MeOH}=$ $1: 1: 2000$ are given in Table 1 .

The $R_{\mathrm{g}} / R_{\mathrm{h}}$ ratio subsequently increases as the size of the particles increases which, in the light of our model studies, can be interpreted in two different ways. First, the as formed aggregates have a density lower than that of the initial particles (the large structures consist of primary particles and solvent molecules). An alternative explanation is the evolution of shape anisotropy because elongated forms tend to show higher $R_{\mathrm{g}} / R_{\mathrm{h}}$ ratios. The second alternative is reinforced by the anisotropic shape of the aggregates revealed by our SEM studies.

The aggregates observed in situ during the second step of the reaction experienced further crystallization and ripening as shown by SEM studies on samples extracted at later stages of the reaction.

\section{Scanning electron microscopy and powder X-ray diffraction}

Complementary SEM investigations were performed for the compositions $\mathrm{Zn}: \mathrm{Him}: \mathrm{MeOH}=1: x: 2000$ with $x=2,4$ and 6 with samples taken after 30, 50 and $240 \mathrm{~min}$. In all cases, this is after the last point of the corresponding TR-SLS experiments. Due to the low concentrations of the investigated

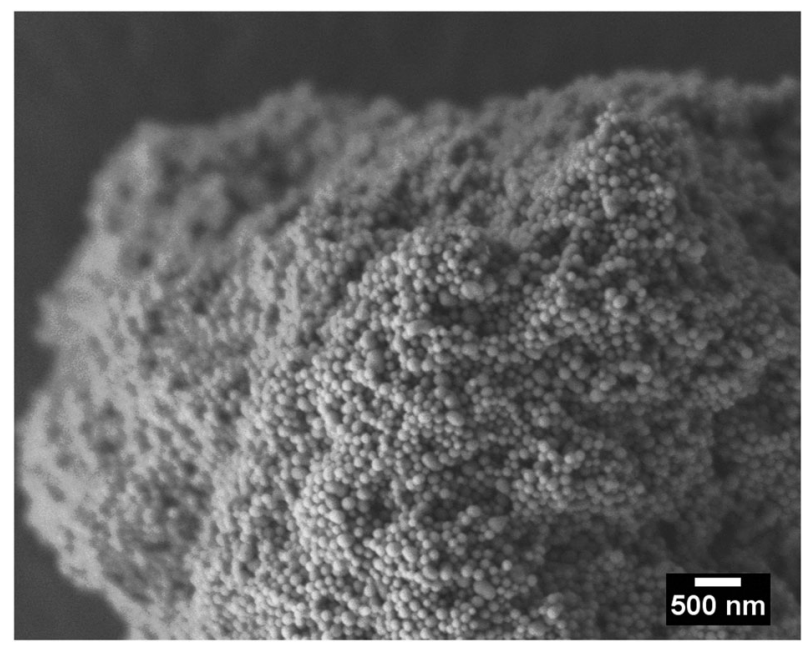

Fig. 14 SEM image showing primary particles on the surface of a secondary aggregate obtained from a growth solution of composition $\mathrm{Zn}: \mathrm{Him}: \mathrm{MeOH}=1: 6: 2000$ after $30 \mathrm{~min}$. 

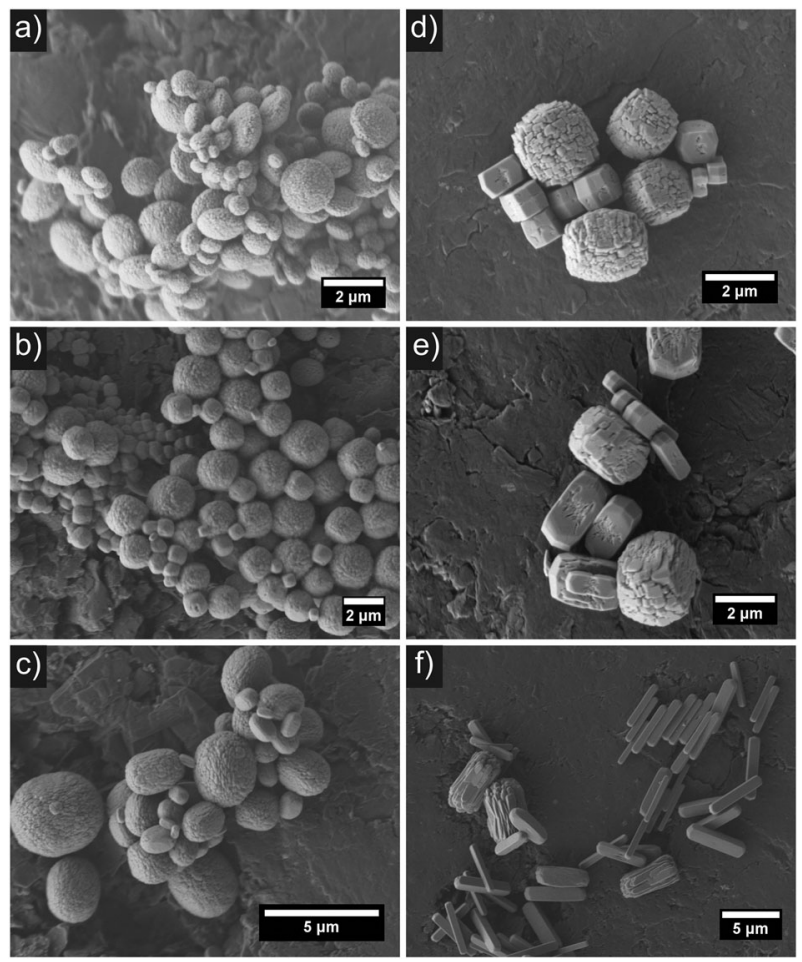

Fig. 15 SEM images showing particles obtained from growth solutions of compositions $\mathrm{Zn}: \mathrm{Him}: \mathrm{MeOH}=1: x: 2000$ and times $t$ : (a) $x=2, t=50 \mathrm{~min}$; (b) $x=4, t=50 \mathrm{~min}$; (c) $x=6, t=50 \mathrm{~min}$; (d) $x=2, t=240 \mathrm{~min}$; (e) $x=4, t=240 \mathrm{~min}$; (f) $x=6, t=240 \mathrm{~min}$.

systems, we could not recover enough solid materials for SEM and XRD experiments from earlier stages.

In the SEM image taken after 30 min (Fig. 14), primary particles on the surface of a secondary aggregate are seen. The rather spherically shaped primary particles have a diameter of about $100 \mathrm{~nm}$, which is in fair agreement with the SLS and DLS results regarding 'monomer' particles.

The secondary aggregates from the three different compositions seen in SEM images taken after 50 min (Fig. 15a-c) clearly reveal rough surfaces and the constituent primary particles. The secondary particles are up to about $3 \mu \mathrm{m}$ in size and their shapes depend on the composition of the growth solutions.

The shapes may be approximately described as oblate spheroids, cubes, and prolate spheroids for $x=2,4$ and 6 , respectively. These specific, non-spherical shapes indicate that the secondary particles are polycrystalline with preferred orientation of the crystalline grains (see below). The crystalline grains are pure ZIF-zni without any other coexisting crystalline phase, as demonstrated by XRD patterns taken from solid samples recovered after about $50 \mathrm{~min}$ (Fig. 16). From the broadening of the diffraction peaks a diameter of 90 to $115 \mathrm{~nm}$ was estimated for the crystallites (see ESI $\dagger$ ), which is in fair agreement with the size of the primary particles determined by SLS and SEM. The proposed description of secondary particle shapes becomes more obvious when we look at the shape and size of the latter particles, as they are seen in the SEM images taken after 240 min (Fig. 15d-f). The secondary particles have not grown in size (it is still about $3 \mu \mathrm{m}$ ) but have evolved into polycrystals with enlarged sizes of the individual grains or

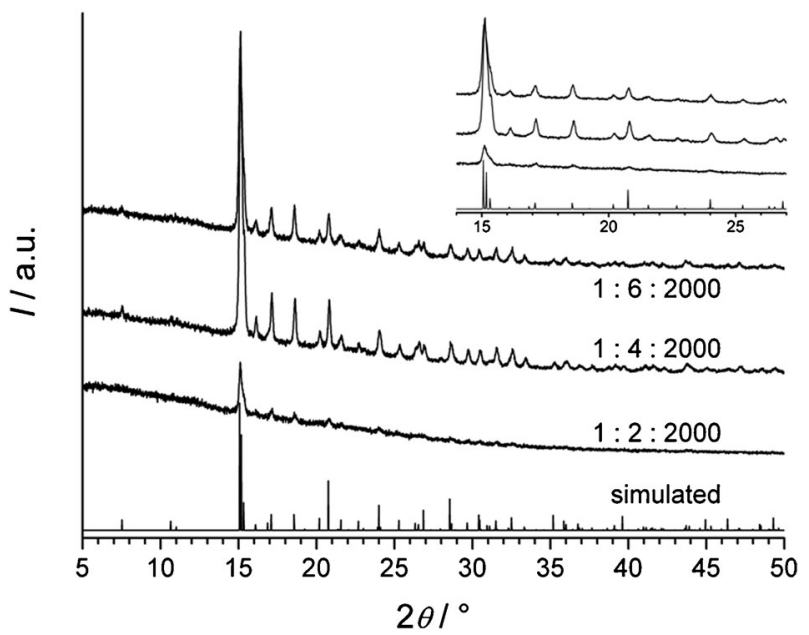

Fig. 16 XRD patterns of intermediate secondary particles after 50 min in comparison with a pattern simulated from ZFI-zni crystal structure data. The solution compositions $\mathrm{Zn}: \mathrm{Him}: \mathrm{MeOH}=$ $1: x: 2000$ are indicated. The inset shows the most significant range of the XRD patterns.

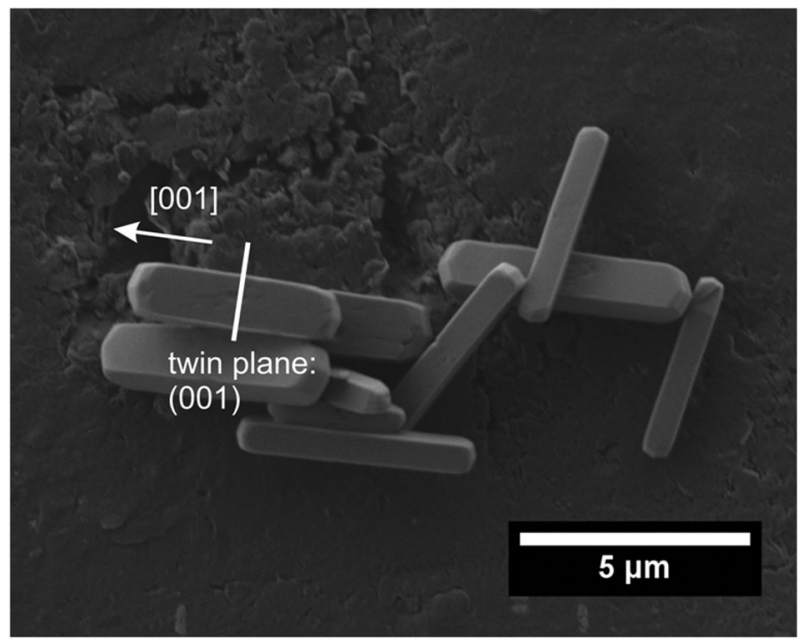

Fig. 17 SEM image showing rod-shaped crystals obtained from growth solution of composition $\mathrm{Zn}: \mathrm{Him}: \mathrm{MeOH}=1: 6: 2000$ after $240 \mathrm{~min}$.

faceted monocrystals with more or less flat surfaces. Obviously, the degree of 'monocrystallinity' increases with decreasing particle size. According to XRD the particles are pure-phase ZIF-zni (see ESI $\dagger$ ).

The habit of the nearly perfect or perfect monocrystals consists of a tetragonal prism and a tetragonal bipyramid (Fig. 17) with the prism axis running parallel to the crystallographic $c$ axis of tetragonal ZIF-zni (space group $I 4_{1} c d$ ). ${ }^{19,20}$ The obvious mirror plane perpendicular to the $c$ axis is not compatible with the polar crystal structure of ZFI-zni (crystallographic point group $4 \mathrm{~mm}$ ) and reveals that the crystals are twins. The aspect ratio of the poly- and monocrystals depends on the composition of the growth solutions and increases from $x=2$ to $x=6$. This can be attributed to a composition dependence of the relative growth rates of the different crystal faces and suggests that the aspect ratio may be controlled by an appropriate choice of the zinc-to-imidazole ratio. A simple 
explanation of the observed phenomenon may be given when comparing the density per unit area of the tetrahedrally coordinated Zn cations with terminal ('dangling') ligands on the $\{100\}$ and $(001) /(00-1)$ faces of a ZIF-zni crystal which constitute the prismatic faces and, as an approximation, the flat bipyramidal faces, respectively (see ESI $\dagger$ for drawings of the atomic arrangements in the faces and further details). This density is larger on the $(001) /(00-1)$ than on the $\{100\}$ faces which means that the growth velocity is higher perpendicular to the former than to the latter faces if all terminal ligands are Him which can contribute to an extension (growth) of the ZFI-zni framework. The lower the concentration of Him in the growth solution, the higher the probability that a terminal ligand position is occupied by a competitive ligand such as $\mathrm{NO}_{3}{ }^{-}, \mathrm{H}_{2} \mathrm{O}$ or $\mathrm{MeOH}$ which cannot contribute to the framework extension resulting in a decrease of the growth velocity. This effect of decreasing Him concentration should predominantly affect those faces which have the highest density of $\mathrm{Zn}$ cations with terminal ligand positions, that is the $(001) /(00-1)$ faces which then become larger compared to the $\{100\}$ faces as observed.

In the SEM image shown in Fig. 15f, polycrystals with a "splitting" morphology are seen. Similar morphologies have been frequently reported for diverse kinds of materials, ${ }^{34}$ including carboxylate-based coordination polymers, ${ }^{35}$ with a pronounced one-dimensional (rod-like) crystal growth, as is the case for the ZIF-zni particle formation from solutions with $\mathrm{Zn}: \mathrm{Him}: \mathrm{MeOH}=1: 6: 2000$.

The secondary aggregates which emanate from a solution of 'monomer' particles during the second stage are unambiguously crystalline ZIF-zni after about $50 \mathrm{~min}$. The origin of the diversification of 'monomers' nucleating secondary particle growth or remaining as 'monomers' in solution has to remain unsettled. Just as unresolved is the question whether this diversification is related to the onset of crystallization.

The observed ZIF-zni formation exhibits similarities with the crystallization of ZIF-8 at room-temperature under similar conditions in the absence of auxiliary monodentate ligands (modulators) ${ }^{16}$ In both cases primary particles form rapidly within seconds upon combining the component solutions. This primary particle formation is characterized by a persistent nucleation of new particles and fast individual growth to a certain size $\left(R_{\mathrm{g}} \approx 20 \mathrm{~nm}\right.$ for ZIF-8, $R_{\mathrm{g}} \approx 60 \mathrm{~nm}$ for ZIF-zni) which depends on the ZIF system and probably also on the particular synthesis conditions. As shown for ZIF-8 by in situ synchrotron SAXS/WAXS,${ }^{17}$ the primary particle nucleation and growth processes run on a time scale of seconds (or even faster) and involve transient formation of small prenucleation nanoclusters. Crystalline ZIF-8 domains are generated rapidly within about $20-35$ s revealing the great propensity of this ZIF system to crystallize as confirmed by a number of further ex situ studies, ${ }^{36}$ one of which indicated the transient coexistence of an amorphous phase. ${ }^{18}$ While the primary ZIF-8 particles are unambiguously crystalline shortly after their formation, the internal structure of the primary ZFI-zni particles is as of yet unknown. Therefore, further experiments devoted to this problem are planned (e.g. in situ synchrotron SAXS/WAXS).

A second stage is also observed during ZIF-8 formation where the primary crystalline ZIF-8 nanoparticles only loosely aggregate in a random fashion and keep their individuality. ${ }^{16}$ These secondary ZIF-8 agglomerates are distinct from the secondary polycrystalline ZIF-zni aggregates. The latter probably have preferred orientation of the crystalline tetragonal grains that undergo further ripening and reconstruction processes. Clearly, the second aggregation stages of ZIF-8 and ZIF-zni formation rely on different colloidal interparticle forces and underlying mechanisms.

As is well known, material properties may depend on the crystal size and shape particularly in the nanoscale range and various methods have been reported to achieve a size and shape control in the case of crystalline coordination polymers. ${ }^{37}$ Coordination modulation, exchange of counter-anions and addition of surfactants have so far been used to control size and shape of ZIFs. ${ }^{16,38}$ To the best of our knowledge, the simple change of the metal-to-bridging ligand ratio has so far not been reported as a method of shape control.

\section{Conclusions}

TR-SLS and TR-DLS experiments revealed that ZIF-zni crystallization follows a two stage mechanism where the first stage involves formation of metastable primary particles with diameters of roughly $120 \mathrm{~nm}$. The duration of the first stage depended strongly on the concentration of the bridging imidazole ligand. The second stage consists of a monomer addition process where the primary particles formed during stage one act as the monomers. The mechanism could be established by fitting the evolution of particle mass and size with time according to a monomer addition mechanism and, alternatively, to cluster-cluster aggregation mechanisms, whereby only the former matched well our experimental TR-SLS data. TR-DLS analysis of the slowest reaction showed that the primary particles consumed during the second stage of the process are replenished over an extended period of time. SEM imaging revealed that further evolution of the secondary particles was a complex process involving polycrystalline intermediates with non-spherical shapes and probably preferred orientations of the crystalline tetragonal grains. Their morphology depended on the $\mathrm{Zn}$ : Him ratio in the initial solutions. Time and location of the first crystallite nucleation events could so far not be established. The pure-phase ZIF-zni crystals obtained after $240 \mathrm{~min}$ are twins. The aspect ratio of the tetragonal crystals can be controlled via the zinc-to-imidazole ratio.

According to the TR-SLS experiments reported here and elsewhere, ${ }^{16}$ the early stages of ZIF-zni and ZIF-8 formation exhibit similarities in that primary particles form rapidly. The nucleation of new primary particles continues over an extended period of time. The processes resulting in the formation of 'monomer' particles take place on a timescale of seconds. Hence, further in situ experiments using techniques of high time resolution that probe different length scales ${ }^{39}$ such as synchrotron small-angle and wide-angle X-ray scattering ${ }^{17,40}$ will have to be performed to gain deeper insights into ZIF-zni nucleation and growth.

\section{Acknowledgements}

Financial support by the DFG Priority Program 1415 "Crystalline Non-equilibrium Phases" (WI1156/3-1, HU 807/14-1) is gratefully acknowledged. 


\section{Notes and references}

1 R. Robson, Dalton Trans., 2008, 5113; G. Férey, Chem. Soc. Rev., 2008, 37, 191.

2 A. Pann, C. Doonan, F. Uribe-Romo, C. Knobler, M. O'Keeffe and O. Yaghi, Acc. Chem. Res., 2010, 43, 58.

3 Y. Tian, C. Cai, Y. Ji, X. You, S. Peng and G. Lee, Angew. Chem., Int. Ed., 2002, 41, 1384.

4 R. Banerjee, A. Phan, B. Wang, C. Knobler, H. Furukawa, M. O'Keeffe and O. Yaghi, Science, 2008, 319, 939.

5 H. Bux, F. Liang, Y. Li, J. Cravillon, M. Wiebcke and J. Caro, J. Am. Chem. Soc., 2009, 131, 16000; C. Gücüyener, J. van den Bergh, J. Gascon and F. Kapteijn, J. Am. Chem. Soc., 2010, 132, 17704.

6 C. Chizallet, S. Lazare, D. Bazar-Bachi, F. Bonnier, V. Lecocq, E. Soyer, A. Quoineaud and N. Bats, J. Am. Chem. Soc., 2010, 132, 12365.

7 G. Lu and J. Hupp, J. Am. Chem. Soc., 2010, 132, 7832.

8 Y. Tian, C. Cai, X. Ren, C. Duan, Y. Xu, S. Gao and X. You, Chem.-Eur. J., 2003, 9, 5673.

9 A. Cheetham and C. Rao, Science, 2007, 318, 58.

10 H. Hayashi, A. Côté, H. Furukawa, M. O'Keeffe and O. Yaghi, Nat. Mater., 2007, 6, 501.

11 Y. Tian, Y. Zhao, Z. Chen, G. Zhang, L. Weng and D. Zhao, Chem.-Eur. J., 2007, 13, 4146.

12 Y. Tian, S. Yan, D. Gu, K. Cui, D. Guo, G. Zhang, Z. Chen and D. Zhao, Chem.-Eur. J., 2010, 16, 1137.

13 I. Baburin, S. Leoni and G. Seifert, J. Chem. Phys. B, 2008, 112, 9437; I. Baburin and S. Leoni, CrystEngComm, 2010, 12, 2809.

14 R. Morris, ChemPhysChem, 2009, 10, 327; F. Millange, M. I. Medina, N. Guillou, G. Férey, K. M. Golden and R. I. Walton, Angew. Chem., Int. Ed., 2010, 49, 763; D. Zacher, R. Schmid, C. Wöll and R. A. Fischer, Angew. Chem., Int. Ed., 2011, 50, 176.

15 X. Huang, Y. Lin, J. Zhang and X. Chen, Angew. Chem., Int. Ed., 2006, 118, 1587; K. Park, Z. Ni, A. Côté, J. Choi, R. Huang, F. Uribe-Romo, H. Chae, M. O'Keeffe and O. Yaghi, Proc. Natl. Acad. Sci. U. S. A., 2006, 103, 10186.

16 J. Cravillon, R. Nayuk, S. Springer, A. Feldhoff, K. Huber and M. Wiebcke, Chem. Mater., 2011, 23, 2130; J. Cravillon, S. Münzer, S.-J. Lohmeier, A. Feldhoff, K. Huber and M. Wiebcke, Chem. Mater., 2009, 21, 1410.

17 J. Cravillon, C. Schröder, R. Nayuk, J. Gummel, K. Huber and M. Wiebcke, Angew. Chem., Int. Ed., 2011, 123, 8217.

18 S. Venna, J. Jasinski and M. Carreon, J. Am. Chem. Soc., 2010, 132, 18030.

19 R. Lehnert and F. Seel, Z. Anorg. Allg. Chem., 1980, 464, 187.

20 E. Spencer, R. Angel, N. Ross, B. Hanson and J. Howard, J. Am. Chem. Soc., 2009, 131, 4022.
21 D. Schubert, M. Visi and C. Knobler, Main Group Chem., 2008, 7,311 .

22 J. Liu, J. Rieger and K. Huber, Langmuir, 2008, 24, 8262.

23 V. Sturm, F. Brandl, D. Engel and W. Hoppe, Acta Crystallogr., Sect. B: Struct. Crystallogr. Cryst. Chem., 1975, 31, 2369; G. Martins, P. Byrne, P. Allan, S. Teat, A. Slawin, Y. Li and R. Morris, Dalton Trans., 2010, 39, 1758.

24 A. Becker and M. Schmidt, Makromol. Chem., Macromol. Symp., 1991, 50, 249.

25 B. Zimm, Chem. Phys., 1948, 16, 1093.

26 G. Berry, Chem. Phys., 1966, 44, 4550.

27 A. Guinier and G. Fournet, Small-Angle Scattering of X-rays, Wiley, New York, 1955, ch. 4.1.1.

28 S. W. Provencher, Comput. Phys., 1982, 27, 213.

29 M. Smoluchowski, Phys. Z., 1916, 17, 585.

30 J. Liu, S. Pancera, V. Boyko, A. Shukla, T. Narayanan and K. Huber, Langmuir, 2010, 26, 17405.

31 M. Lin, H. Lindsay, D. Weitz, R. Ball, R. Klein and P. J. Meakin, Phys. Rev. A, 1990, 41, 2005.

32 M. Lin, H. Lindsay, D. Weitz, R. Klein, R. Ball and P. Meakin, Phys. Condens. Matter, 1990, 2, 3093.

33 W. Burchard, Adv. Polym. Sci., 1983, 48, 1.

34 J. Tang and A. Alivisatos, Nano Lett., 2006, 6, 2701; H. Deng, C. Liu, S. Yang, S. Xiao, Z. Zhou and Q. Wang, Cryst. Growth Des., 2008, 8, 4432; W. Wang, L. Zhen, C. Xu and W. Shao, Cryst. Growth Des., 2008, 8, 1734; Z. Gu, T. Zhai, B. Gao, D. Ke, Y. Ma and J. Yao, Cryst. Growth Des., 2007, 7, 825.

35 K. Liu, H. You, G. Jia, Y. Zheng, Y. Huang, Y. Song, M. Yang, L. Zhang and H. Zhang, Cryst. Growth Des., 2010, 10, 790.

36 Y. Pan, Y. Liu, G. Zeng, L. Zhao and Z. Lai, Chem. Commun., 2011, 47, 2071; M. Zhu, S. R. Venna, J. B. Jasinski and M. A. Carreon, Chem. Mater., 2011, 23, 3590.

37 A. Carné, C. Carbonell, I. Imaz and D. Maspoch, Chem. Soc. Rev., 2011, 40, 291; W. Lin, W. J. Rieter and K. M. L. Taylor, Angew. Chem., Int. Ed., 2009, 48, 650.

38 Y.-S. Li, H. Bux, A. Feldhoff, G.-L. Li, W.-S. Yang and J. Caro, Adv. Mater., 2010, 22, 3322; Y. Pan, D. Heryadi, F. Zhou, L. Zhao, G. Lestari, H. Su and Z. Lai, CrystEngComm, 2011, 13, 6937.

39 N. Pienack and W. Bensch, Angew. Chem., Int. Ed., 2011, 50, 2014; M. O'Brien, A. Beale and B. Weckhuysen, Chem. Soc. Rev., 2010, 39, 4767.

40 E. Stavitski, M. Goesten, J. Juan-Alcaniz, A. Martinez-Joaristi, P. Serra-Crespo, A. V. Petukhov, J. Gascon and F. Kapteijn, Angew. Chem., Int. Ed., 2011, 50, 9624; J. Juan-Alcaniz, M. Goesten, A. Martinez-Joaristi, E. Stavitski, A. V. Petukhov, J. Gascon and F. Kapteijn, Chem. Commun., 2011, 47, 8578. 